\title{
Examining a Flow-Usage Model to Understand MultiMedia-Based Learning
}

\author{
Raafat George Saadé, Serge Elgaly, and Fassil Nebebe \\ John Molson School of Business, Concordia University, \\ Montreal, Quebec, Canada
}

\author{
raafat.saade@gmail.com sgaly@sympatico.ca \\ fnebebe@jmsb.concordia.ca
}

\begin{abstract}
The effective crafting of multi-media for e-learning depends on understanding usage. Research work in that regard is scarce. In this paper, we propose a theoretical model to understand usage in that context. We construct a flow-usage model with three dimensions of usage: frequency of use, time spent, and interruptions. A survey methodology approach was administered to capture relevant constructs. A structural equation model approach was used for the assessment of the model's results. Structural equation analysis provides evidence of significance for motivation on beliefs and attitudes on usage.
\end{abstract}

Keywords: Multimedia, E-learning, Performance, Cognitive Absorption, Usage

\section{Introduction}

In essence, multimedia is the use of a number of different content formats to convey information. Text, animation, video, audio, and graphics are examples of common types of content format used (Hwang \& Yi, 2003; Lin, 2004; Saadé \& Galloway, 2005). A multimedia learning information system would use two or more content formats in a cohesive way, such that it would relate a message from the sender to the receiver (that is from the teacher to the student). The combination of content types creates the learning effect with a medium that is able to yield specific beneficial learning results (Mayer \& Moreno, 2002).

Web-technologies over the last five years have made the use of web-based multimedia systems easier to build, integrate, and deliver. There are three technological factors that have eased the adoption of multimedia use:

1. The increase in demand for e-learning,

2. The shared open knowledge initiatives at the academic levels and,

Material published as part of this publication, either on-line or in print, is copyrighted by the Informing Science Institute. Permission to make digital or paper copy of part or all of these works for personal or classroom use is granted without fee provided that the copies are not made or distributed for profit or commercial advantage AND that copies 1) bear this notice in full and 2) give the full citation on the first page. It is permissible to abstract these works so long as credit is given. To copy in all other cases or to republish or to post on a server or to redistribute to lists requires specific permission and payment of a fee. Contact Publisher@InformingScience.org to request redistribution permission.
3. The open source and standards for e-learning systems.

Recent work has attempted to draw a line between research and practice. The question on whether multimedia has positive effects on learning and in what instances does multimedia affects learning (Graff, 2003) has not been clearly answered yet. Other research has also questioned the interface design as it 
would influence user's feeling of boredom (Lindh \& Soames, 2004; Tait, 1998), and. although it has not considered the interactivity between the multimedia tool for learning and the student, this still remains unanswered.

From a beliefs perspective, the intention to use an information system has been researched extensively (Saadé, Nebebe, \& Mak, 2011). Many different cognitive models of learning have been suggested, studied, and reengineered to yield the greatest explanation. Often these models have been based on social psychology or sociology and then formatted specifically for information system study use (Saadé, 2010; Venkatesh, Morris, Davis, \& Davis, 2003). This assimilates the benefits of the years of study performed by social scientists to information science study. However, usage in this group of research is scarce.

In the past 20 years, there has been a multitude of studies that were based on the assumption that exposure to the content of a subject is sufficient to induce learning (Gupta, Quaddus, \& Wachter, 2000; Saadé \& Huang, 2008). As a result to this assumption, research has considered a measurement of 'intention to use' as a valid justification for the use of multimedia (or any online type of content for that matter) in the e-learning phenomenon. This assumption is flawed in so many ways due to the complex psychological state of intentions leading to action (actual usage in the present context). Nevertheless, there were some (all be it, few) studies on usage, and although these studies have analyzed usage of information systems, none to our knowledge have applied it in the e-learning multi-media context and have decomposed usage into three dimensions: time spent using the system (TS), frequency of use (FREQ), and interruptions while using the system (INT).

This is the purpose of our paper: to explore learner's usage of a multimedia system through the lens of a flow-usability-belief paradigm. This study was performed by proposing a motivational model integrated with cognitive absorption and usage dimensions.

\section{Research Model}

When the subject matter involves technology and behavior, the technology acceptance model (TAM) comes first to mind. The TAM is a well-developed and well-documented model for testing the determinants of users' intention to use a specific technology. Davis, the creator of the TAM, posited that Perceived Ease of Use (PEU) and Perceived Usefulness (PU) are antecedents of a users' intention to use (Davis 1989). The TAM is based partially of the Theory of Reasoned Action (TRA) (Fishbein \& Ajzen, 1975). The TRA explains a person's behavior based on his or her perception of what people, who are important to the person, think about his or her behavior. This concept of others' influence on a user is otherwise known as subjective norm (SN).

PEU can be defined as the amount of effort that a user believes is required to use a system. PU is the extrinsic benefit as a result of usage. These two factors make up a large portion of what could be the equivalent of attitude toward behavior in the TRA. The inclusion of SN is usually restricted to use in studies where collaboration or group work is present. Attitude was included in the original TAM but was later removed because it was believed to have a weak influence on intention (I). Subsequent studies have shown that in some situations, particularly those with multimedia content, attitude (ATT) can sufficiently influence I (Galloway \& Saade, 2005; Yang \& Yoo, 2003). ATT is also included in models that incorporate the theory of planned behavior with TAM.

The TAM was also extended to include cognitive absorption (CA). In relation to the present study, the multimedia tool called MMERD (which stands for MultiMedia for Entity Relationship diagram) is not comparable to a software or a website, which are the environments mostly studied by the TAM. Our study is unique in the sense that the technology used is a multimedia tool and 
that it is used for learning, both of which are more complex that software/websites and training, respectively.

Bahli and Saade (2005) suggested that cognitive absorption was an appropriate addition to insure that the entertainment benefits of multimedia applications were taken into account. The factors that measure the added benefit to the user of the MMERD are focused immersion, control, curiosity, temporal dissociation, and heightened enjoyment (Agarwal \& Karahanna, 2000). A similar structure has been used to measure the usage of videogames (Hsu \& Lu, 2004). The MMERD is designed in a way so that it is similar to that of a strategy puzzle game. The rules of the game of course would be the same as those taught for the design of Entity Relationship Diagrams (ERDs). The interactivity of the MMERD is also a similarity with videogames. The affects of cognitive absorption, sometimes referred to as flow experience, are full involvement solely to the task at hand, heightened satisfaction of the task, temporal dissociation, and stronger beliefs toward user control (Hedman, Montegomery, \& Sharafi, 2004). Heightened enjoyment was added to this model to capture the intrinsic reward mechanism when a person's skills and a demand for skills are matched. Similarly focused immersion is the dissociation with one's real environment due to the blocking of all perceptions except for those required to complete the task (Ainley, Howard, \& Pearce, 2004).

An exploration of the effects of CA could not fully be considered complete unless it is modeled with a factor, which could be assumed to be the opposite. Consequently, we have also factored in a construct we shall call interruption (INT). Confusion as a result of interruption has often been cited as cause for disturbances and intrusive thoughts in online learning and performance (Caputi $\&$ Smith, 2007; DeYoung \& Spence, 2004). The factors that make up this construct are measurements of self reported general computer problems during use and interruptions faced during the use of the actual tool. Common problems resulting from these factors are hindered memoryprocessing capabilities, more time and errors during the task and more time to complete tasks (Beckers, Rikers, \& Schmidt, 2006).

Another additional construct we chose to include was a measure of effort. Effort is measured objectively from the amount of time spent (TS) and the frequency (FREQ) of use of the MMERD. These constructs were added as possible moderators to intention to use via the interruption as shown in Figure 1. TS and FREQ are actual usage measurements of the MMERD. Based on the above, we posit the following hypotheses:

H1. Cognitive Absorption will have a positive relationship with Perceived Ease of Use.

H2. Perceived Ease of Use will have a positive relationship with Intrinsic Motivation.

H3. Perceived Ease of Use will have a positive relationship with Extrinsic Motivation.

H4. Perceived Ease of Use will have a positive relationship with Attitude.

H5. Intrinsic Motivation will have a positive relationship with Attitude.

H6. Extrinsic Motivation will have a positive relationship with Attitude.

H7. Attitude will have a positive relationship with Frequency of use.

H8. Attitude will have a positive relationship with Time Spent using the MMERD.

H9. Frequency of Use will have a positive relationship with Interruptions.

H10. Time Spent will have a positive relationship with Interruptions.

H11. Extrinsic Motivation will have positive relationship with Intention to Use.

H12. Frequency of Use will have a positive relationship with Intentions.

H13. Interruptions will have a negative relationship with Intention to Use.

H14. Time spent will have a positive relationship with Intentions. 


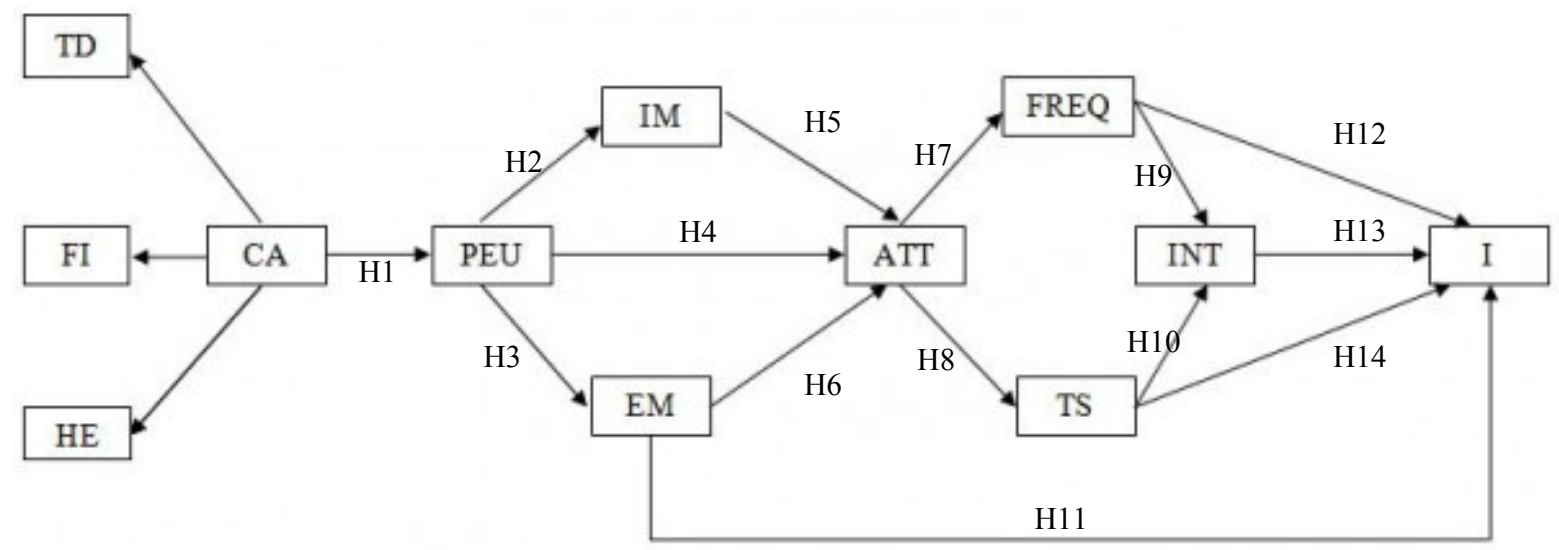

Figure 1. Proposed research model

Figure 1 includes 8 constructs and one variable (TS) totaling 14 hypotheses. The resulting network, which is strongly based on previous research work, proposes an interesting and elaborate psychological theory that links cognition to emotion (via motivational states) then to usage. The proposed research model can be viewed as three sub-networks: the first is the cognitive subnetwork which includes CA and PEU; the second is the motivational sub-network composed of IM, EM, and ATT; and the third entails the usage sub-network which includes FREQ, TS and INT. This model is unique in several ways since usage studies in the MIS domain are relatively scarce and 'emotion-IT' related research is regarded to be very important and necessary. The idea of intentions as part of the model constructs set, although used overwhelmingly, is questionable due to the fact that intention is a complex psychological phenomenon that we still know little about. Yet we use it as a globally encompassing construct.

Therefore, we can rationalize from the proposed research model that the experience with a multimedia tool for learning can be described/understood through a cognitive $\rightarrow$ motivational $\rightarrow$ usage impact chain. Intuitively, this makes sense since our first experience with the multimedia tool is processed by our cognitive capacities. It is expected that consequent to that, motivational states are developed based on the expectations resulting from the first cognitive experiences, leading to usage behavior reflected in terms of interruptions, frequency of use and time spent using the multimedia tool.

\section{The Multi-Media Learning Tool}

The MMERD (Multimedia Entity Relationship Diagram) is a web- based learning tool. The purpose of this tool is to give students a chance to understand and learn how to build ERD's in an interactive medium. MMERD uses Entity Relationship and flowchart symbols to logically represent the relationships of entities within a database. The operation of the MMERD is similar to that of any CASE tool application. The user is given a whiteboard for workspace and access to a number of ERD symbols. The symbols provided are entities, relationships, and cardinalities (many and one). Where the operation of the MMERD and any CASE tool differ is in the freedom allowed to the user. In the MMERD the user must place the correct ER symbol in the right order. The time in which the user took to complete the move is also recorded. In this fashion the MMERD is similar to a puzzle game online, where the ERD symbols are the pieces. The entity specifications used in each problem are supplied by a case given to the user at the beginning of each session. There is only one fully correct answer to each case but there are multiple ways of solving each case depending on the case. 


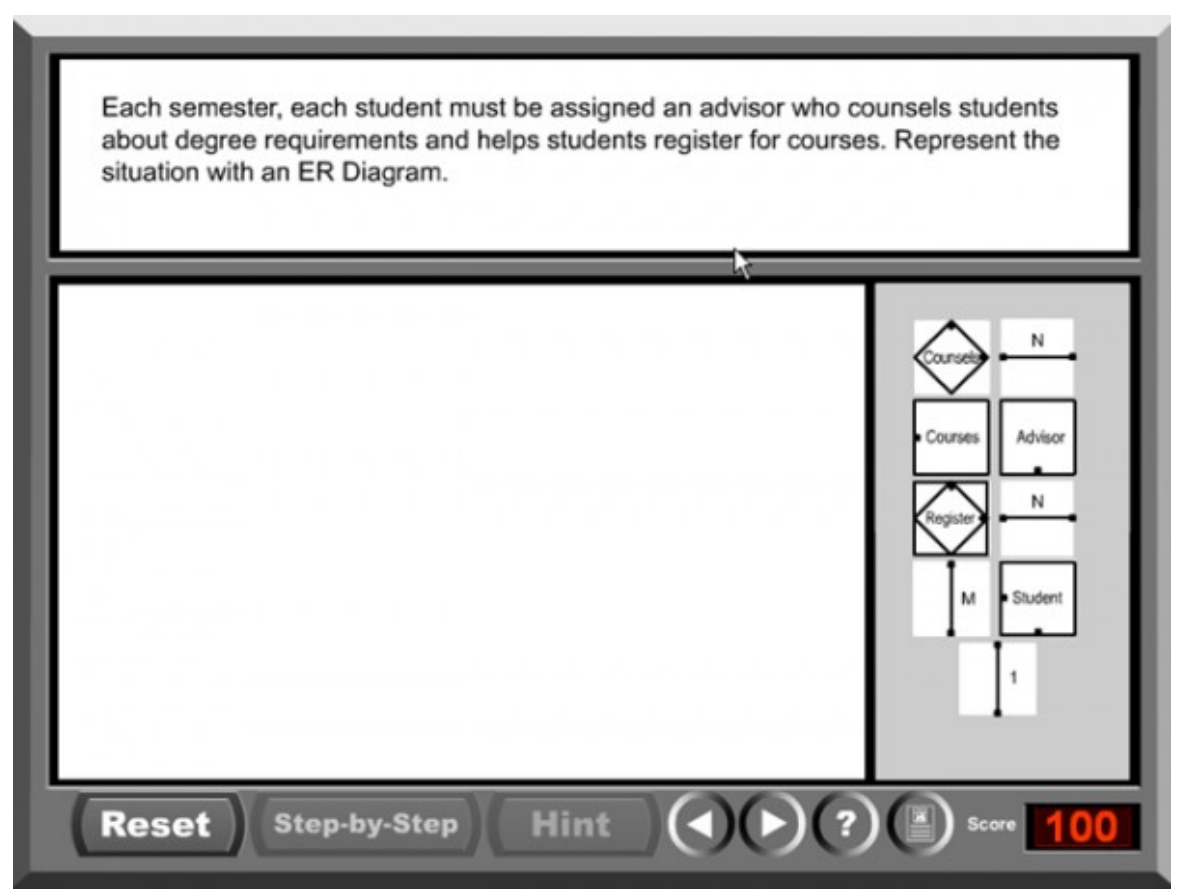

Figure 2. MMERD interface

The users of this tool are students attending Concordia University in Montreal, Canada. The tool is available to all students taking an online Management of Information Systems course offered under the John Molson School of Business. This class is a 300 level commerce core class. The developers of the MMERD are faculty at the University. Programmers of this tool are also students at Concordia University in the faculty of Computer Science.

The MMERD is hosted on the university's servers and is reached through a link of the online classes' main site. This tool was made available to the students throughout the semester. In a general session using the MMERD a student logs on to a server hosting the classes' material and is presented with varying study materials and methods. These range from online quizzes and power point presentations to a class BLOG. After selecting the MMERD site the student is given the option to view a number of successive pages, which describe how to create ERDs or to use the MMERD to do practice problems. Once the MMERD interface is loaded (shown in Figure 2) the student is presented with a case, which describes the business situation for the database and characteristics of the relationships between the entities for which the business would like to capture data.

The student then selects the relationship or entity symbol, which they believe is appropriate and places it on the white board space (see Figure 3 below). Movement of symbols is permitted at all times within the whiteboard. If the student places the wrong entity symbol with the wrong relationship symbol the symbol being used is returned to the tool case and 10 points are removed from their total. 


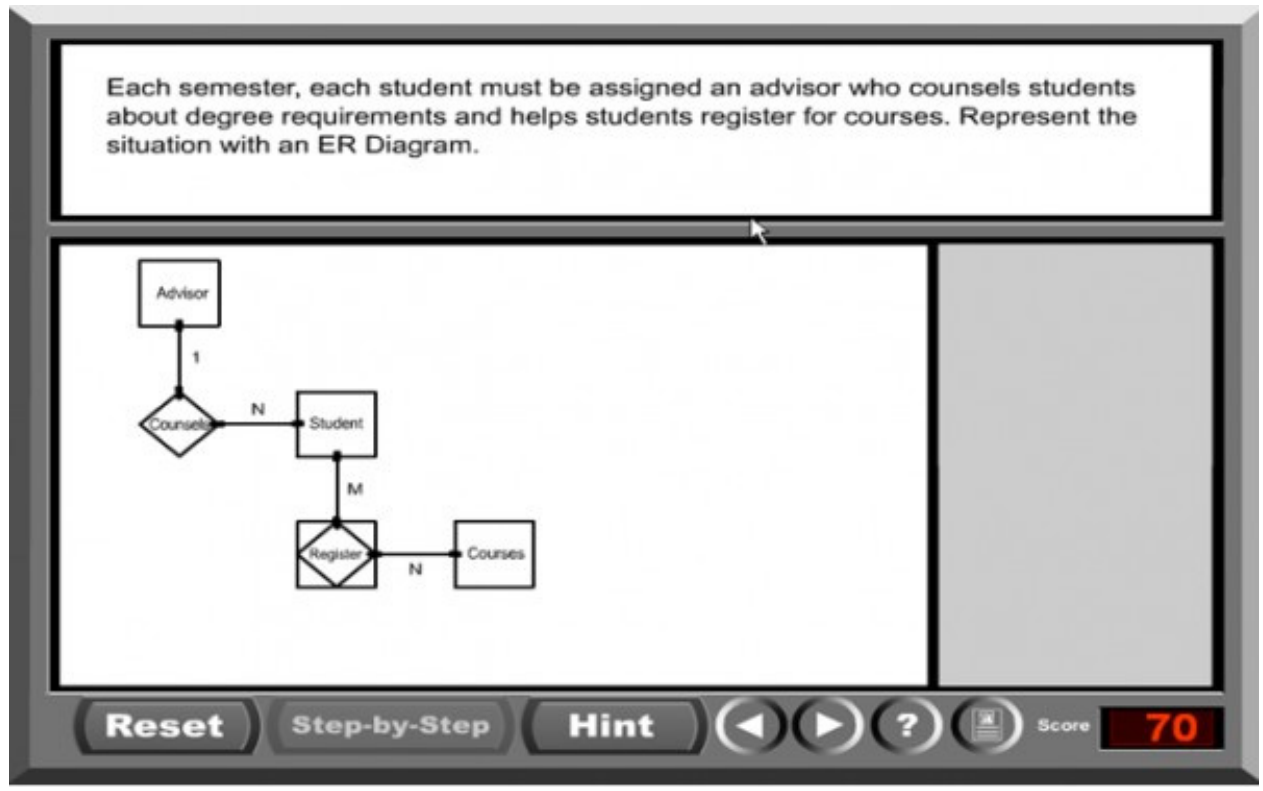

Figure 3. MMERD with completed example

There is no limit to the number of times that the student can try different symbols, but they are given the option to view a hint after their score drops to 70. At any point during the session the student can view a help sheet (Figure 4), return to the main page or to scroll through other questions. Upon completion of the correct ERD the student is congratulated and given an option to continue with another ERD or to return to the main page.

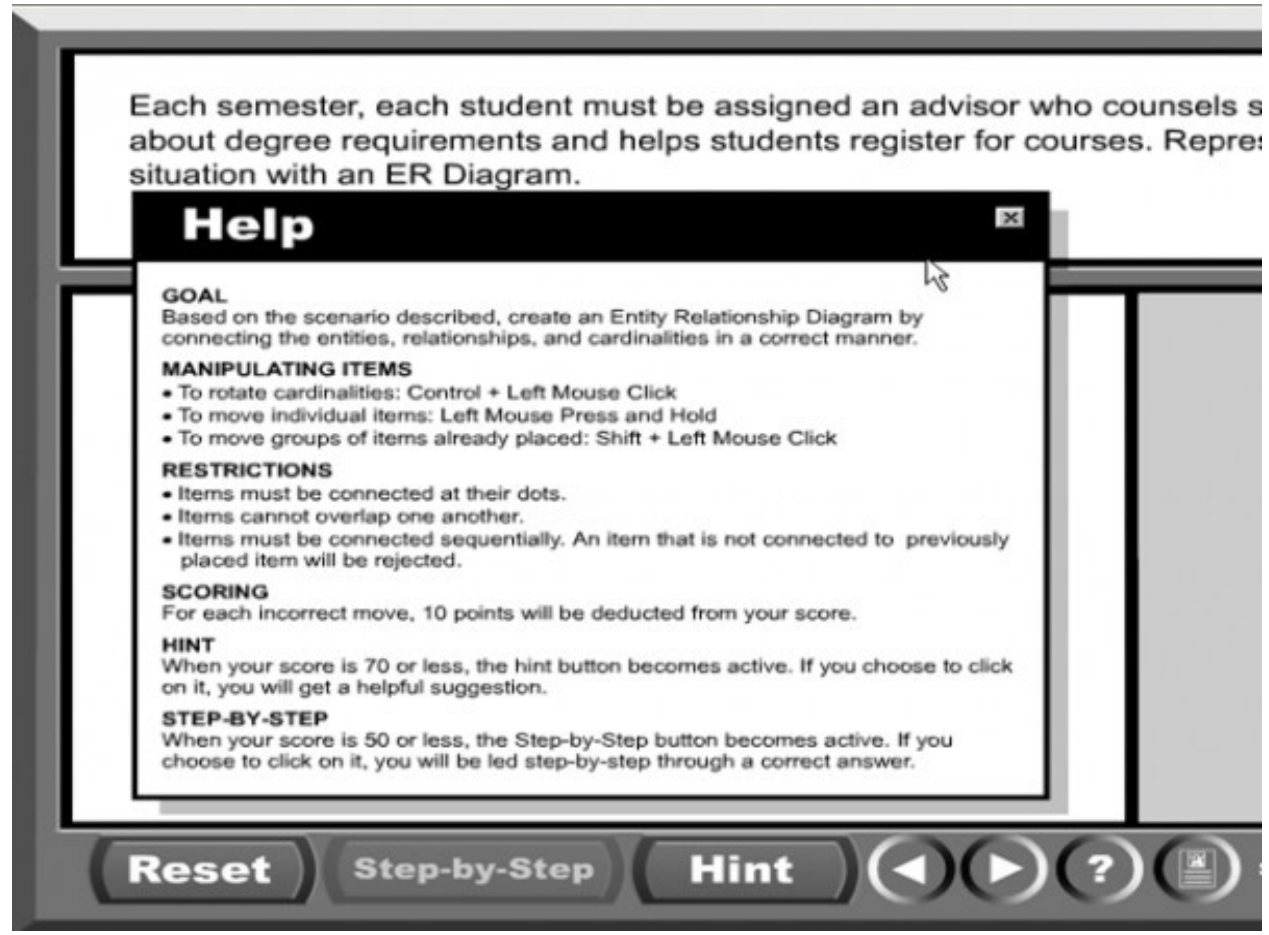

Figure 4. MMERD with the help feature 


\section{Methodology}

This study was performed using responses collected from 100 students at the John Molson School of Business. Surveys were completed after the final exam of an introductory course in management of information systems. This was done at the end of two sequential semesters. This course is a mandatory core course for all commerce students. The class covered material related to the technical function of computer systems, website creation, and system development tools. This class was offered online and used multiple forms of online educational methods. Use of the MMERD was not mandatory and, therefore, not all students used the MMERD. Only students who did use the MMERD were asked to fill out the survey and did so voluntarily. No reimbursement was offered for filling out the survey.

EQS was the software selected to calculate the structural equation modeling. This software was selected due to its high acceptance within the information study research community (Chin, 1998; Hsu \& Lu, 2004). This statistical software is used to find the factor variation and path correlation. Another reason for the selection of this software is that it performs calculations on the entire system synchronously. To perform the descriptive and confirmatory analysis Prostat was used.

The survey itself was 55 questions long. The questions measured responses using a 5-point Likert scale ranging from strongly disagree to strongly agree. Statements were offered in both the positive and the negative order in order to mitigate non-valid responses. Statements were stylized through literature review of related research (Davis, 1989).

Performance measurement is based on the student's actual grade achieved during the midterm or final exam. The section on the exams used to measure student's performance gave the students a short paragraph describing a business situation. Using this paragraph the students could derive entities, attributes, relationships, and cardinalities. The students were then asked to create a simplified ERD diagram. The maximum points to be awarded for this section was 10 and the direct grade out of ten was used in the PER construct.

\section{Results and Analysis}

Table 1 displays the results of the descriptive statistics. From these calculations one can see that there is relatively little deviation from the mean in the conceptual constructs. This could mean that the users believed use of the MMERD was not only beneficial to their study but also was very agreeable to use. Rho was calculated as a measure of reliability for the latent variables. The value of .5 is set as the benchmark for verified reliability; all variables used in this paper attained the required benchmark except for INT. It can thus be concluded that all constructs in the model are internally consistent except for INT.

Table 1. Descriptive statistics of constructs
\begin{tabular}{|l|c|c|} 
Construct & Mean & St. Dev \\
\hline CA & 3.04 & 0.81 \\
\hline PEU & 3.53 & 1.05 \\
\hline IM & 3.44 & 0.98 \\
\hline EM & 3.53 & 0.94 \\
\hline ATT & 4.04 & 0.92 \\
\hline Freq & 2.04 & 1.01 \\
\hline TS & 2.19 & 1.02 \\
\hline INT & 3.52 & 1.29 \\
\hline I & 3.54 & 0.97 \\
\hline
\end{tabular}

The factor analysis results are shown in Figure 5. Varimax rotation was used to calculate the factor loadings. This type of analysis was performed to insure that all statements within the survey 
did measure the desired variable. In review of requirements for factor loading analysis, in order for a loading to be considered valid the loading must be greater than 0.5 . The highlighted cells are the loadings of the related items (columns and rows).

\begin{tabular}{|c|c|c|c|c|c|c|c|c|c|c|c|c|c|c|c|c|c|c|c|c|c|c|}
\hline & FREQ & SPENT & INTERUP & PEU1 & PEU2 & PEU3 & PEU4 & pU1 & PU2 & pU3 & Pu4 & ATI1 & AITL & AाT3 & INT1 & INT2 & MOT1 & MOT2 & MOT3 & TD & FE & HE \\
\hline FREQ & 1.040 & & & & & & & & & & & & & & & & & & & & & \\
\hline SPENT & 0.258 & 1.044 & & & & & & & & & & & & & & & & & & & & \\
\hline INTERUP & 0.120 & 0.036 & 1.685 & & & & & & & & & & & & & & & & & & & \\
\hline PEU1 & -0.065 & 0.030 & 0.540 & 1.079 & & & & & & & & & & & & & & & & & & \\
\hline PEU2 & -0.010 & 0.092 & 0.359 & 0.591 & 1.121 & & & & & & & & & & & & & & & & & \\
\hline PEU3 & 0.038 & 0.167 & 0.236 & 0.649 & 0.643 & 1.085 & & & & & & & & & & & & & & & & \\
\hline PEU4 & 0.007 & 0.164 & 0.427 & 0.840 & 0.808 & \begin{tabular}{|l|}
0.798 \\
\end{tabular} & 1.200 & & & & & & & & & & & & & & & \\
\hline PU1 & 0.307 & 0.162 & 0.400 & 0.386 & 0.265 & \begin{tabular}{|l|}
0.331 \\
\end{tabular} & 0.386 & 0.932 & & & & & & & & & & & & & & \\
\hline PU2 & 0.290 & 0.144 & 0.287 & 0.329 & 0.288 & 0.260 & 0,389 & 0.636 & 0.866 & & & & & & & & & & & & & \\
\hline PU3 & 0.272 & 0.249 & 0.362 & 0.316 & 0.318 & 0.310 & 0,428 & 0.612 & 0.658 & $0.867 \mid$ & & & & & & & & & & & & \\
\hline PU4 & 0.267 & 0.150 & 0.177 & 0,485 & 0.377 & 0.478 & 0.533 & 0.583 & 0.585 & 0.546 & \begin{tabular}{|l|l|}
0.882 \\
\end{tabular} & & & & & & & & & & & \\
\hline ATT1 & 0.102 & 0.127 & 0.075 & 0.253 & 0.127 & 0.155 & 0.183 & 0.331 & 0.288 & 0.268 & 0.374 & 0.817 & & & & & & & & & & \\
\hline ATा2 & 0.027 & 0.078 & 0.098 & 0.295 & 0.156 & 0.187 & 0.262 & 0.292 & 0.276 & 0.227 & 0.388 & \begin{tabular}{|l|}
0.717 \\
\end{tabular} & 0.938 & & & & & & & & & \\
\hline $\mathrm{ATI3}$ & 0.115 & 0.090 & 0.032 & 0.253 & 0.179 & 0.159 & 0.218 & 0.278 & 0.286 & 0.202 & 0.360 & 0.717 & 0.745 & 0.798 & & & & & & & & \\
\hline INT1 & 0.276 & 0.196 & -0.018 & 0.321 & 0.225 & 0.324 & 0.373 & 0.361 & 0.346 & 0.275 & 0.510 & 0.462 & 0.487 & 0.470 & 0.829 & & & & & & & \\
\hline INT2 & 0.312 & 0.212 & 0.074 & 0.390 & 0.355 & 0.335 & 0.498 & 0.320 & 0.375 & 0.345 & 0.490 & 0.392 & 0.460 & 0.384 & 0.748 & 1.084 & & & & & & \\
\hline MOT1 & 0.223 & 0.169 & 0.187 & \begin{tabular}{|l|}
0.437 \\
\end{tabular} & 0.488 & 0.427 & 0.572 & 0.328 & 0.324 & 0.358 & 0.526 & 0.321 & 0.443 & 0.361 & 0.512 & 0.550 & \begin{tabular}{|l|}
0.899 \\
\end{tabular} & & & & & \\
\hline MOT2 & 0.269 & 0.226 & 0.138 & 0.400 & 0.407 & 0.365 & 0.464 & 0.404 & 0.392 & 0,416 & 0.562 & 0.373 & 0.415 & 0.365 & 0.567 & 0.563 & 0.767 & \begin{tabular}{|l|}
0.917 \\
\end{tabular} & & & & \\
\hline MOT3 & 0.294 & 0.256 & 0.115 & 0,406 & 0.430 & 0.518 & 0,544 & 0.413 & 0.469 & 0,555 & \begin{tabular}{|l|}
0.647 \\
\end{tabular} & \begin{tabular}{|l|l|}
0.345 \\
\end{tabular} & 0,404 & 0.333 & 0.614 & 0.648 & 0.785 & 0.862 & 1.112 & & & \\
\hline TD & 0.324 & 0.415 & 0.081 & 0.080 & 0.238 & 0.165 & 0.180 & 0.176 & 0.244 & 0,368 & 0.290 & 0.172 & 0.151 & 0.140 & 0.253 & 0.234 & 0.365 & 0.470 & 0.527 & 1.038 & & \\
\hline FE & 0.387 & 0.227 & 0.092 & 0.286 & 0.192 & 0.296 & 0.294 & 0.295 & 0.338 & 0.407 & 0.400 & 0.126 & 0.164 & 0.132 & 0.255 & 0.321 & 0.366 & 0.435 & 0.529 & 0.437 & 0.811 & \\
\hline HE & 0.111 & 0.111 & 0.088 & 0.165 & 0.218 & 0.236 & 0.263 & 0.155 & 0.129 & 0.182 & 0.204 & 0.083 & 0.132 & 0.094 & 0.196 & 0.226 & 0.243 & \begin{tabular}{|l|}
0.212 \\
\end{tabular} & \begin{tabular}{|l|}
0.261 \\
\end{tabular} & 0.129 & 0.212 & 0.280 \\
\hline
\end{tabular}

Figure 5. Factor analysis results

The results presented in Figure 5 show that all items load more significantly with their related items than they do with items measuring other factors, with the exception of heightened enjoyment (HE-loading factor $=0.28)$. This verifies that, with the exception of HE, all statements did assess their prescribed factor. Nevertheless, we decided to retain HE for the next set of analysis.

Calculations of the average variation extracted were performed to further strengthen the discriminant validity. These values are calculated by comparing the value of the average variation extracted of a variable on its own factor to the average variance extracted of a variable on other factors. It is expected that the factor should load higher on its own than on that of any other. According to the results this is true of the data collected in this study.

The proposed model was tested using structural equation modeling (SEM) technique. Through this modeling we can determine the degree to which the proposed model explains the constructs selected using the collected data. This strength of support is called the R-squared value. Rsquared is essentially the percentage of variance within the construct that is explained by the preceding constructs of the model. The R-squared values calculated for the present model are shown within the construct box in Figure 6. The path coefficients are also show lying on the paths in this diagram. The path coefficients represent the strength of the influence of the preceding construct on the construct itself.

The R-squared values are presented in Table 2. Strong R-squared values were calculated for: $\mathrm{INT}=90 \%$; I $=99 \%$; TS $=95 \%$. However, $\mathrm{PEU}=25 \%$; $\mathrm{EM}=32 \%$; IM $=25 \%$; and ATT $=25 \%$ have significantly smaller R-squared values, with FREQ being the weakest at $19 \%$. 
Table 2. Model paths characteristics

\begin{tabular}{|l|c|c|}
\hline \multicolumn{1}{|c|}{ Relationship } & Path & R-squared \\
\hline CA - PEU & $0.497^{*}$ & 0.247 \\
\hline PEU - EM & $0.566^{*}$ & 0.320 \\
\hline PEU - IM & $0.502^{*}$ & 0.252 \\
\hline PEU - ATT & $-0.540^{*}$ & 0.251 \\
\hline EM - ATT & $0.233^{*}$ & 0.251 \\
\hline IM - ATT & $-0.094^{*}$ & 0.251 \\
\hline ATT - TS & $-0.972^{*}$ & 0.945 \\
\hline ATT - FREQ & $0.430^{*}$ & 0.185 \\
\hline TS - INT & $-0.971^{*}$ & 0.897 \\
\hline FREQ - INT & $-0.751^{*}$ & 0.897 \\
\hline EM - I & $-0.047^{*}$ & 0.987 \\
\hline TS - I & $2.667^{*}$ & 0.987 \\
\hline FREQ - I & $1.391^{*}$ & 0.987 \\
\hline INT - I & $2.393^{*}$ & 0.987 \\
\hline
\end{tabular}

The path coefficients shown were all found to be significant to $p<0.05$. Figure 6 shows that the impact of IM $\rightarrow$ ATT (H5) and that of EM $\rightarrow$ ATT (H6) is small with path coefficients equal to 0.094 and 0.233 respectively. The only influence on ATT is from PEU (H4) with a value of 0.540 . We can also observe that the usage paths of the model described by FREQ, TS, INT and I are very strong and intuitively correct in the direction of influence. We highlight in point form the major finding from the results of the SEM as shown in Figure 6:

- Cognitive absorption has a strong influence on perceived ease of use of the MMERD.

- Perceived ease of use has a strong and equal influence on motivations, both intrinsic and extrinsic, and on attitudes. This implies that PEU influences different affective states equally. Therefore, it is evident that the results show a stable impact of multi-media type information technology on perceptions, beliefs and affect/emotions.

- At the same time motivation does not seem to alter attitudes, thereby implying the possibility that although students get motivated based on the information system characteristics, however, this motivation does not alter how they feel about it.

- Yet, their attitude towards the information system (in this case a multi-media based learning tool) strongly influence their usage in the following ways:

- As attitude of students is more positive, the frequency of using it (FREQ) also increases,

- As students' attitude increases they seem to spend less time using it. This may be explained by the impact chain of PEU $\rightarrow$ ATT $\rightarrow$ TS \& FREQ - Students who view the system easy to use also feel less positive about it because they may associate the value of the system by the challenge they get in using it. Consequently, they spend less time using it than those who feel the system more difficult to use,

- Students who spend more time using the system and use it more frequently seem to have less interruption using it.

- Evidently, the results show that usage have a great impact on intention to use the system further. 


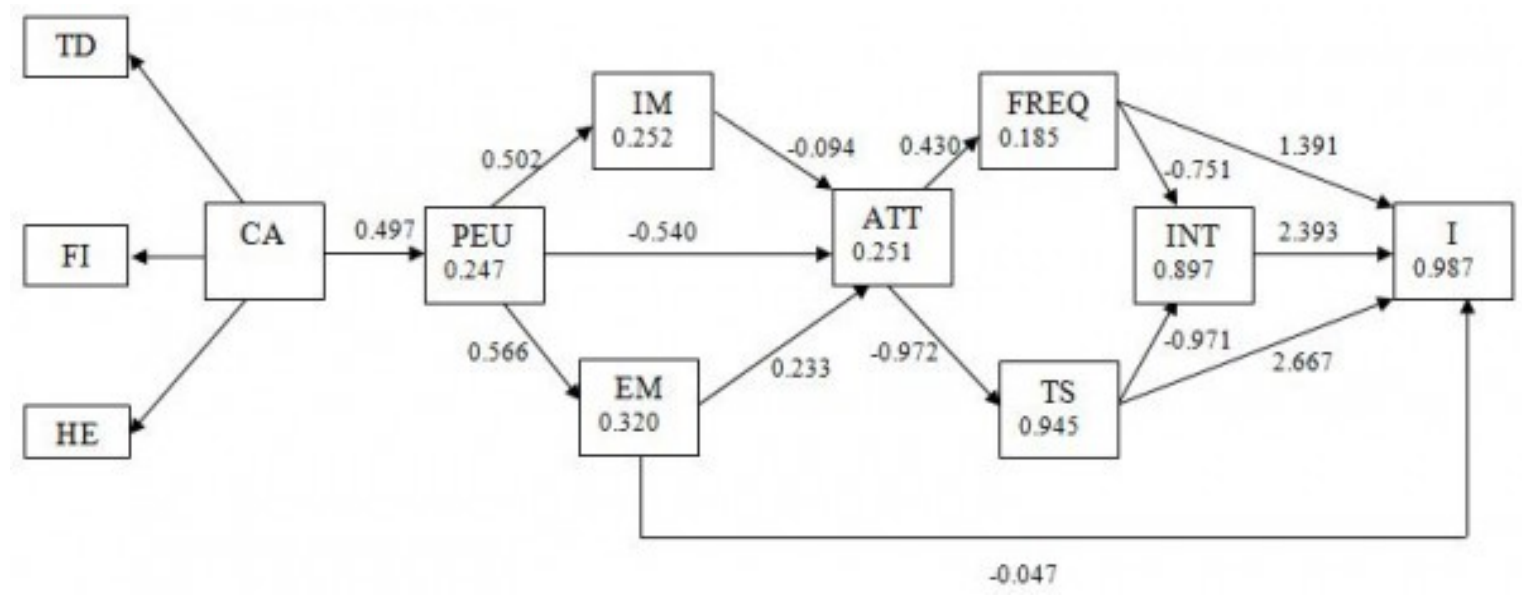

Figure 6. Structural equation model results using EQS

Looking at the results of the SEM through the lens of the cognitive-motivation-usage theory discussed in the previous 'research model' section, we observe that cognition seems to strongly influence motivational states. This represents a link between 'rational thoughts' and 'emotional senses' experiences that are exposed during the repeated interaction between the user and the tool. The influence between the motivational and affective (ATT) states is weak, indicating the independent cognitive processing of IM, EM, and ATT. It follows that attitudinal (which may be thought to represent affect) state strongly influence usage (described by FREQ and TS) with TS providing much more explanation of variance than FREQ. These results provide great insight to the potential of the cognitive-emotional-usage model to explain multimedia experiences.

\section{Conclusions}

This study was motivated by the lack of research related to objective usage data of information systems, and more specifically, the use of multi-media learning systems. In was evident from this study that attitudes are not influenced by motivational mechanisms and are impacted only by usability of the multi-media learning system. The SEM results of the proposed research model showed a clear impact of attitude on usage described primarily by frequency of use, time spent using it, and interruptions, which in turn predicted a significant amount of the variance determining students' intentions (98.7\%).

As a major contribution of the TAM being modeled in terms of usability-beliefs-usage paradigm, we characterized usage with three dimensions: frequency of use, time spent, and interruptions all three measure objectively. The success of this model in terms of usage is the ability of information technology to store this information. The implications are directed towards creating the proper learning objects/tools/systems as it will be used for the proper context and in the proper environment.

As with any study the present study is not without its own limitations. Subjective data always has its constraints. The perceptions, beliefs, and attitudes about the MMERD cannot be directly recorded and interpreted and must be analyzed with the use of a questionnaire. This method causes inaccuracies because the answers recorded can be affected by the participants' subjectivity. Since the questionnaires were not completed by all students at the same time, this method also suffers from temporal effects. Questionnaires are only capable of measuring the user at a certain point of time and not throughout their experiences or when the user is presented with another similar tool. 
The student learning experience using the MMERD depends on the course context. For example, the way in which the MMERD is used in the course, as given by the following questions, play an important role in the student's perception of their learning experience:

- Was the activity graded?

- If so, then were the grades given for participation or based on performance?

- How much percent was the MMERD activity allocated as part of the total course grade?

- Was the use of the MMERD open for the entire semester or for a short period of time?

- Were the examples used in the MMERD similar to those in the exam?

Unlike many studies where students are questioned on an application that is intended for business or daily work related operation purposes, this study uses students to measure an application designed for student's learning. Therefore there is a better fit between the purpose of the tool and the study context.

The strength of this study is two-fold. First it uses an information system built specifically for learning objectives. Second, three important dimensions to usage were studied and analyzed. Since this study only attempts to reflect the impact of usage on intention to use multimedia based online learning tools it does not suffer from the broadness of most TAM studies.

Further research will have to be done to expand our finding into the design research domain where specific information systems are built for controlled usage.

\section{Acknowledgement}

This research work was made possible with the support of eConcordia (Montreal, Canada) and Social Sciences and Humanity Research Council (SSHRC) seed grants.

\section{References}

Ainley, M., Howard, S. \& Pearce, J. M. (2004). The ebb and flow of online learning. Computers in Human Behavior. 21(5), 745-771.

Agarwal, R., \& Karahanna, E. (2000). Time flies when you're having fun: Cognitive absorption and beliefs about information technology usage. MIS Quarterly, 24, 4, 665-694.

Beckers, J. J., Rikers, M. J. P., \& Schmidt, H. G. (2006). The influence of computer anxiety on experienced computer users while performing complex computer tasks. Computers in Human Behavior, 22(3), 456466.

Caputi, P., \& Smith, B. (2007). Cognitive interference model of computer anxiety: Implications on computer-based assessment. Computers in Human Behavior, 23(3), 1481-1498.

Chin, W. (1998). Issues and opinions on structural equation modeling. Management Information Systems Quarterly, 22, 1.

Davis, F. D. (1989). Perceived usefulness, perceived ease of use, and user acceptance of information technology. Management Information Systems Quarterly, 13, 319-339.

DeYoung, C. G., \& Spence, I. (2004). Profiling information technology users: En route to dynamic personalization. Computers in Human Behavior, 20(1), 55-65.

Fishbein, M., \& Ajzen, I. (1975). Belief, attitude, intention, and behavior. Reading, MA: Addision-Wesley.

Galloway, I., \& Saade, R. (2005). Understanding intention to use multimedia information systems for learning. Journal of Issues in Informing Science and Information Technology, 2.

Graff, M. (2003). Cognitive styles and attitudes towards using online learning and assessment methods. Electronic Journal of E-learning, 1(1), 21-28. 
Gupta, J. N. D., Quaddus, M. A., \& Wachter, R. M. (2000). IT takes a village: Virtual communities in support of education. International Journal of Information Management, 20(6), 473-489.

Hedman, L., Montegomery, H., \& Sharafi, P. (2006). Using information technology: Engagement modes, flow experience, and personality orientations. Computers in Human Behavior, 22(5), 899-916.

Hsu, C., \& Lu, H. (2004). Why do people play on-line games? An extended TAM with Social influences and flow experience. Information and Management, 41, 853-868.

Hwang, Y., \& Yi, M., (2003). Predicting the use of web-based information systems: self-efficacy, enjoyment, learning goal orientation, and the technology acceptance model. International Journal of Human-Computer Studies, 59, 431-449.

Lin, D. (2004). Evaluating older adults' retention in hypertext perusal: Impacts of presentation media as a function of text topology. Computers in Human Behavior, 20, 491-503.

Lindh, J., \& Soames, C. (2004). A dual perspective on an online university course. Electronic Journal of ELearning, 2(1), 129-134.

Mayer, R. E., \& Moreno, R. (2002). Animation as an aid to multimedia learning. Educational Psychology Review, 14(1), 87-99.

Saadé, R. (2010). Cognitive mapping decision support for the design of web-based learning environments. International Journal of Web-Based Learning and Teaching Technologies, 5(3), 36-53.

Saade, R., \& Bahli, B. (2005). The impact of cognitive absorption on perceived usefulness and perceived ease of use in online learning: an extension of the technology acceptance model. Information and Management, 42(2), 317-327.

Saadé, R., \& Galloway, I. (2005), Understanding the acceptance of multimedia applications for learning, Issues in Informing Science and Information Technology, 2, 287-296.

Saadé, R., \& Huang, Q. (2008). Meaningful learning in discussion forums: Towards discourse analysis. Issues in Informing Science and Information Technology, 6, 87-99.

Saadé, R., Nebebe, F., \& Mak, T. (2011). Knowledge management systems development: Theory and practice. Interdisciplinary Journal of Information, Knowledge and Management, 6, 35-72. Retrieved from http://www.ijikm.org/Volume6/IJIKMv6p035-072Saade472.pdf

Tait, K. (1998). Replacing lectures with multimedia CBL: Student attitudes and reactions. Instructional Science, 26, 409-438.

Venkatesh, V., Morris, M. G., Davis, G. B., \& Davis, F. D. (2003). User acceptance of information technology: Toward a unified view. MIS Quarterly, 27(3), 425-478.

Yang, H. \& Yoo, Y. (2003). It's all about attitude: Revisiting the technology acceptance model. Decision Support Systems. 


\section{Biographies}

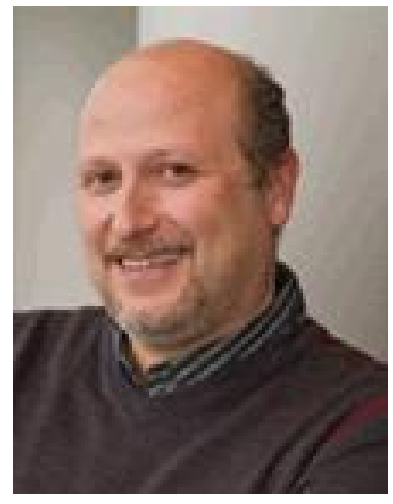

Dr. Raafat George Saade has been teaching in the faculty since 1998. He obtained his Ph.D. in 1995 (Concordia University) after which he received the Canadian National Research Council postdoctoral fellowship, which he completed at McGill University in Montreal. Dr. Saade has published in journals such as Information \& Management, Decision Sciences, and Expert Systems with Applications. His research interests include the development and assessment of information systems, and the supply chain of digital in-formation products.

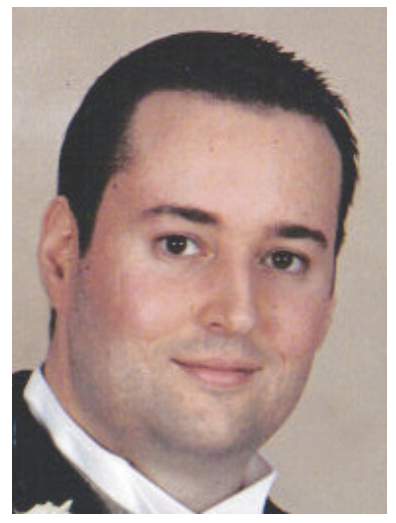

Mr. Elgaly has 13 years experience in Project Management, eLearning, Decision Support Systems, eHearlth, and quality control/assurance. He is a member of the Beta Gamma Sigma and the Golden Key International Hon-ors Societies. Mr. Elgaly obtained a Bachelor of Science (Bsc) degree in Physiology from McGill University, and a Bachelor of Commerce (BComm) degree in Management Information Systems from Concordia University. Mr. Elgaly is interested in research and plans to continue his studies towards a $\mathrm{PhD}$ degree.

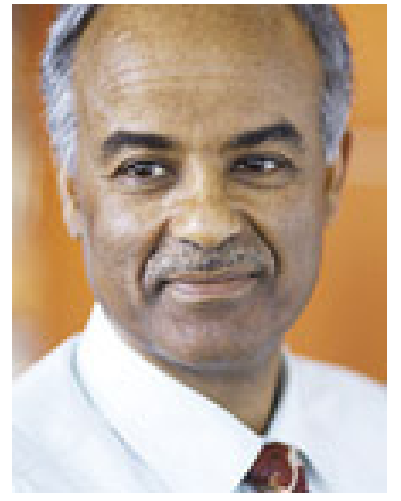

Dr. Nebebe is a Professor and Chair of the Department of Decision Sciences \& M.I.S. of Concordia University, Montreal, Canada. His $\mathrm{Ph} . \mathrm{D}$. in Statistics is from Queen's University at Kingston, Ontario, Canada. His academic training has been in Bayesian modeling and has made scholarly contributions in Bayesian and empirical Bayes shrinkage estimation. Currently his research focuses on methods using the bootstrap, heteroscedastic regression models, small area estimation, Gibbs sampling, modeling parameter designs and statistical computing. He had served as Managing Editor (2004-2007) of SSC LIAISON The Quarterly Newsletter Magazine of the Statistical of Canada, and he is the founding President of the Statistical Society of Ethiopians in North America (SSENA). Since 1995 he has been an International Advisory Board member of SINET: Ethiopian Journal of Science, and JESA: Journal of the Ethiopian Statistical Association. 